\title{
Surgical Treatment of a Giant Vagal Paraganglioma
} \author{
Stefanov Kiuri ${ }^{1}$ and Álvaro Fernández Heredero ${ }^{1}$ \\ ${ }^{1}$ Department of Vascular Surgery, Hospital Universitario La Paz, Madrid, Spain \\ ${ }^{2}$ Department of Oral and Maxillofacial Surgery, Hospital Universitario La Paz, Madrid, Spain \\ ${ }^{3}$ Departamento de Angiología y Cirugía Vascular, Planta Hospital General, Madrid, Spain
}

Alexia Paluso Montero', Luis Riera del Moral*1, José Luis Cebrian Carretero², Teresa Hernandez Ruiz ${ }^{1}$, Stefan

Submission: May 04, 2018; Published: May 23, 2018

*Corresponding author: Luis Riera del Moral, Department of Vascular Surgery, Hospital Universitario La Paz, Madrid, Spain,

Email: Luis.riera@salud.madrid.org

\begin{abstract}
Vagal Paragangliomas (PG) are rare tumours which represent approximately $5 \%$ of all head and neck paragangliomas. We describe the rare case of a giant recidivant unilateral vagal PG of $4 \mathrm{~cm} \times 4.5 \mathrm{~cm}$ in CAT Scan which required embolization and posterior surgical resection. After surgery the patient presented isolated episodes of nausea and dysphonia until discharge from the hospital with remaining dysphonia.

Abbreviations: PGs: Paragangliomas; CAT: Computerized Axial Tomography; PVA: polyvinyl alcohol; US: Ultrasound; MRI: Magnetic Resonance Imaging; EBRT: External Beam Radiotherapy; SRS: Stereotactic Radio surgery
\end{abstract}

\section{Introduction}

Paragangliomas (PGs) are tumours from extra-adrenal paraganglionic tissue derived from neural crest cells. PGs may be located in four main sites when arise in head and neck: the carotid bifurcation, the jugular bulb, the tympanic plexus and the vagal ganglia [1]. These tumours are usually benign and slowly growing. Most of the ones located in the head and neck belong to the nonchromaffin PG group. Vagal PGs are rare tumours which represent approximately $5 \%$ of all head and neck paragangliomas [2]. The clinical manifestation is a palpable, painless mass in the upper neck that can displace the tonsil anteriorly. Horner's syndrome and deficit of cranial nerves 10 to 12 may occur [3]. We describe the rare case of a giant recidivant unilateral vagal PG which required surgical resection. Patient consent for publication of the case report was obtained.

\section{Case Report}

A 51 year old woman with no relevant medical history. The patient had a surgical resection of a carotid PG performed 14 years ago, release of carpal tunnel syndrome, breast nodule exeresis and a caesarean section. At physical exploration presents a pulsatile laterocervical mass which has grown and causes discomfort when swallowing, and can only be manipulated laterally. An Angiographic Computerized Axial Tomography (CAT) scan was performed as a part of the study, which revealed a hipervascular tumour. The tumour was located between the Carotid Artery and the Internal Yugular Vein. The size in CAT scan was $4 \mathrm{~cm} \times 4.5 \mathrm{~cm}$ compatible with the diagnosis of vagal PG (Figure 1).

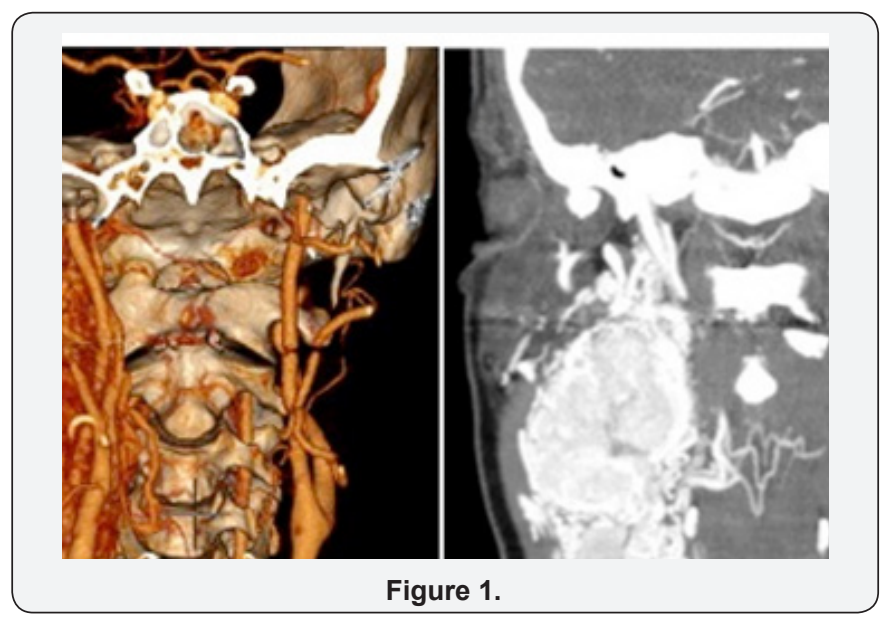

48 hours prior to surgical resection, transfemoral approach embolization of more than $80 \%$ of the vascularisation was performed with polyvinyl alcohol (PVA) particles and coils (Figure 2). Surgical resection was programmed the day after embolization (Figure 3). After surgery the patient presented isolated episodes of nausea and dysphonia until discharge from the hospital. One year after the procedure dysphonia remained as a residual symptom due to partial vocal cord paralisys, probably due to recurrent laringueal nerve damage during resection, but no tumour recurrence was found. 


\section{Global Journal of Otolaryngology}

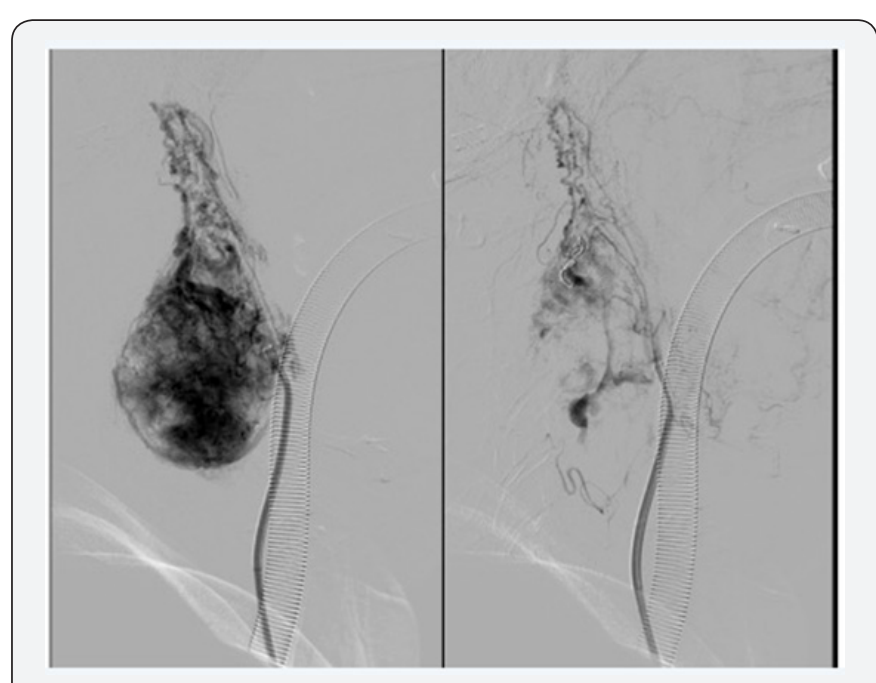

Figure 2.

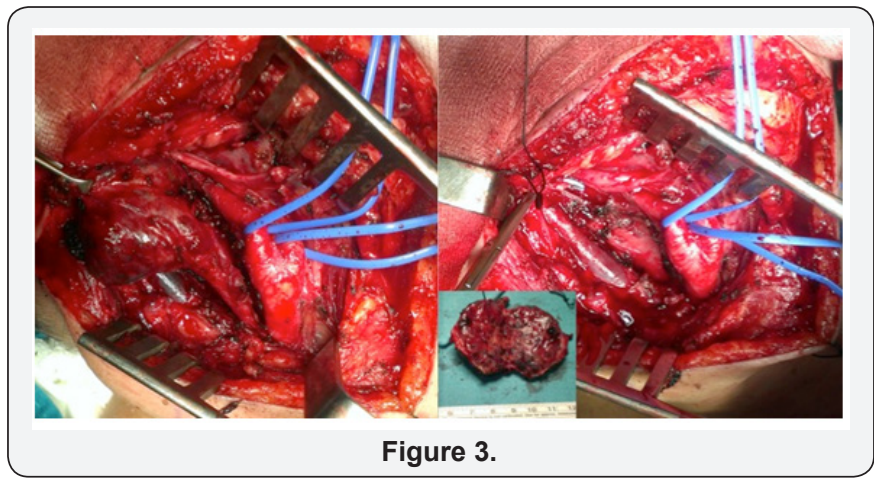

Discussion

Vagal PG can be located near the base of the skull where surgical excision may require a multispecialty team. Similar to glomus jugulare, the outcomes depend on the size of the tumour and the involvement in adjacent structures [4]. These two are often locally aggressive. When located lower in the neck, surgical resection is easier and implies less perioperative morbidity. Usually, the complete resection of these tumours requires vagal nerve sacrifice. There has been a report of successful laryngeal re-inervation after tumour resection and neuroplasty [5].

Diagnosis of carotid PGs with Ultrasound (US) is part of the study, thus for diagnosis of vagal PGs it is not sufficient, for it cannot delineate the tumour. Intensive homogeneous contrast enhancement of solid tumoursis demonstrated in high resolution Computerized Tomography scans. Contrast-enhanced Magnetic Resonance Imaging (MRI) can be performed to locate the tumour accurately. MRI provides precise visualization of intracranial involvement in advanced tumours and can be helpful to make a differential diagnosis [6].

Surgical treatment is the only treatment which can offer complete tumour elimination. Because of their vascularity and the involvement of vascular and neural structures, total excision implies high morbidity [7]. Low morbidity is provided in patients with a good medical condition, the size of the tumour and the location. In order to offer surgical or radiotherapy as treatments rather than observation, symptoms or radiological progression must be demonstrated. It is defined as an increase in the volume of more than $20 \%$ in one year. In vagal PGs, surgery is reserved for patients who already have a vagal nerve palsy [7]. This is the reason why surgery was the treatment chosen for our case.

Surgery can result in nerve damage with speech and swallowing difficulties like disphasia and aspiration or dysphonia [2]. The rate of nerve palsies is higher with surgery than with External Beam Radiotherapy (EBRT). EBRT is reserved for patients who cannot undergo surgery because of advanced age, comorbidity, unresectable tumours or residual disease. The goal of EBRT is to provide disease control [8]. Some authors consider cure after EBRT as the absence of tumour progression leaving an asymptomatic residual mass which can regress but not disappear completely. Stereotactic Radio surgery (SRS) has not been described as a treatment for vagal PG. Although SR is well recognized for jugular PG treatment with fewer cranial nerve palsies [7]. SR does not guarantee a total resection of the tumour. It is an option for those tumours of the base of the skull $<3 \mathrm{~cm}$ which cannot undergo RT. Although there is few data referring to SRS, local control seems to be excellent. In contrast, the risk of hearing loss is approximately $50 \%$ [3]. A retrospective review revealed similar results of local tumour control with SRS and EBRT, and a lower risk of morbidity compared with surgery. Patients with advanced age and a limited life expectancy with asymptomatic tumours can be treated with observation.

Embolization prior to surgical resection reduces tumoural size and vascularisation and makes excision easier with less blood loss. It should be performed 48 hours before surgery in order to avoid local inflammatory changes that could make resection difficult. This technique, can be beneficious prior to surgery. Complications such as distal embolization, necrosis or stroke may occur as a consequence of this procedure. In order to determine the arterial supply and the extent of tumour vascularity, selective angiographic injections of the internal and external carotid arteries are performed. Carotid body PGs are successfully embolized through transfemoral transarterial access. Direct puncture of embolizing materials has been described. This technique has the inconvenient of important complications such as migration of the material into intracranial circulation. Some authors have reported the use of balloons to protect intracranial circulation while performing tumour embolization [9-11].

\section{Conclusion}

Vagal PG is infrequent. Most usually it is benign tumour which presents as a slowly growing, painless, upper neck mass. Surgery was performed as the treatment of this case because of the symptoms. It can benefit from previous embolization of the tumour. EBRT should be offered to elder patients with comorbidities that cannot undergo surgery. EBRT has successful 
results in tumour control and low morbidity related to the treatment. Another emerging possible treatment is SRS. Although SRS may have promising results, there is few data published.

\section{References}

1. Kunzel J, De J, Mantsopoulos K, Koch M, Baussmerth M, Zenk J, et al (2014) Experiences in the treatment of patients with multiple head and neck paragangliomas. Am J Otolaryngol- Head Neck Med Surg. Elsevier Inc 35(3): 294-9.

2. Netterville JL, Jackson CG, Miller FR, Wanamaker JR, Glasscock ME (1998) Vagal paraganglioma: a review of 46 patients treated during a 20-year period. Arch Otolaryngol Head Neck Surg 124(10): 11331140.

3. Gilbo P, Morris CG, Amdur RJ, Werning JW, Dziegielewski PT, Kirwan J, et al. (2014) Radiotherapy for benign head and neck paragangliomas: a 45 -year experience. Cancer 120(23): 3738-3743.

4. Corssmit EP, Romijn JA (2014) Clinical management of paragangliomas. Eur J Endocrinol 171(6): 231-243.

5. Lamarre ED, Lorenz RR, Milstein C, Scharpf J (2011) Laryngeal reinnervation after vagal paraganglioma resection: A case report. In American Journal of Otolaryngology - Head and Neck Medicine and Surgery 32(2): 171-173.
6. Szymanska A, Szymański M, Czekajska-Chehab E, Gołąbek W, SzczerboTrojanowska M (2014) Diagnosis and management of multiple paragangliomas of the head and neck. Eur Arch Oto-Rhino-Laryngology 1991-1999.

7. Suárez C, Rodrigo JP, Bödeker CC, Llorente JL, Silver CE, et al. (2013) Jugular and vagal paragangliomas: Systematic study of management with surgery and radiotherapy. Head and Neck p 35(8): 1195-1204.

8. Dupin C, Lang P, Dessard-Diana B, Simon JM, Cuenca X, Mazeron JJ, et al. (2014) Treatment of head and neck paragangliomas with external beam radiation therapy. Int J Radiat Oncol Biol Phys 89(2): 353-359.

9. Taieb D, Kaliski A, Boedeker CC, Martucci V, Fojo T, et al. (2014) Current approaches and recent developments in the management of head and neck paragangliomas. Endocr Rev 35(5): 795-819.

10. Ozyer U, Harman A, Yildirim E, Aytekin C, Akay TH, et al. (2010) Devascularization of head and neck paragangliomas by direct percutaneous embolization. Cardiovasc Intervent Radiol 33(5): 967975.

11. Kalani MYS, Ducruet AF, Crowley RW, Spetzler RF, McDougall CG, et al (2013) Transfemoral transarterial onyx embolization of carotid body paragangliomas: Technical considerations, results, and strategies for complication avoidance. Neurosurgery 72(1): 9-15.

\section{Your next submission with Juniper Publishers} will reach you the below assets

- Quality Editorial service

- Swift Peer Review

- Reprints availability

- E-prints Service

- Manuscript Podcast for convenient understanding

- Global attainment for your research

- Manuscript accessibility in different formats ( Pdf, E-pub, Full Text, Audio)

- Unceasing customer service

Track the below URL for one-step submission https://juniperpublishers.com/online-submission.php 